\title{
PENERAPAN TRI HITA KARANA PADA MANAJEMEN SATRIA AGROWISATA DI KECAMATAN TAMPAKSIRING, KABUPATEN GIANYAR
}

\author{
The Application Of Tri Hita Karana In Satria Agrowisata Management \\ At Tampaksiring Subdistrict, Gianyar Regency
}

\author{
Desak Putu Padmidewi, Wayan Windia, and I Made Sudarma
}

Program Studi Magister Agribisnis, Fakultas Pertanian, Universitas Udayana, Bali, Indonesia

E-mail: padmidewi208@gmail.com

\begin{abstract}
Tri Hita Karana has becomes the foundation of development in the Province of Bali, its reflected in the vision of the development in the Province of Bali in 2006-2026 "Bali Dwipa Jaya, Fair, and Democratic, and Safe and Unified". Tri Hita Karana has becomes the foundation of development in Bali, the Tri Hita Karana must be applied to various community activities such as politics, economics, socials, defenses, and securities. Satria Agrowisata has application the Tri Hita Karana concept. The research aimed to analyzed the suitability between expectations and realities on the application of Tri Hita Karana at Satria Agrowisata, to analyzed the connection of application of Tri Hita Karana with management of Satria Agrowisata, and to analyzed satisfied visitors of Satria Agrowisata toward agrotourism activities with Tri Hita Karana application. Data of this research were used qualitative and quantitative. The research location is in Satria Agrowisata was chosen by purposive. The researchs were used two types of sampling methode such as census sampling and accidental sampling. Collection of data in the research were used several methods such as observations, interviews, and documentations. To analyzed the data, the research were used descriptive qualitative analysis method and Rank Spearman correlation. The results of the researchs were show the suitability between expectations and realities on the application of Tri Hita Karana at Satria Agrowisata is very suitable. The connection between Tri Hita Karana and management in agrotourism is very weak. Visitors of Satria Agrowisata were very satisfied with agrotourism activities in Satria Agrowisata which Tri Hita Karana application. The suggestions are to continue the application of Tri Hita Karana in activities agrotourism, to improve the connection between the application of Tri Hita Karana and management at the Agrotourism, and Satria Agrowisata needs to improve the quality of their service and add varieties of drinks and foods.
\end{abstract}

Key words: Tri Hita Karana, Management, Satria Agrowisata

\begin{abstract}
ABSTRAK
Provinsi Bali telah menjadikan Tri Hita Karana sebagai landasan pembangunannya, yang tercermin dari visi pembangunan Provinsi Bali tahun 2006-2026 yakni:"Bali Dwipa Jaya, Adil, dan Demokratis, serta Aman dan Bersatu". Tri Hita Karana telah menjadi landasan pembangunan di Bali. Tri Hita Karana wajib diterapkan pada berbagai kegiatan kemasyarakatan seperti politik, ekonomi, sosial, pertahanan, serta keamanan masyarakat. Satria Agrowisata sudah menerapkan konsep Tri Hita Karana, namun dalam penerapannya ada yang tidak sesuai dengan harapan. Berdasarkan hal tersebut penelitian ini bertujuan untuk menganalisis kesesuaian antara harapan dan kenyataan pada penerapan Tri Hita Karana di Satria Agrowisata, menganalisis hubungan penerapan Tri Hita Karana dengan manajemen Satria Agrowisata, dan menganalisis kepuasaan konsumen terhadap kegiatan agrowisata di Satria Agrowisata yang menerapkan Tri Hita Karana. Data penelitian yang digunakan adalah kualitatif dan kuantitatif. Penelitian dilakukan di Satria Agrowisata. Penelitian menggunakan dua macam penentuan sampel yaitu sensus sampling dan accidental sampling. Pengumpulan data pada penelitian ini menggunakan beberapa metode yaitu observasi, wawancara, dan dokumentasi. Penelitian ini menggunakan metode analisis deskripstif kualitatif untuk data penelitian kualitatif dan korelasi Rank Spearman untuk data penelitian kuantitatif. Hasil penelitian menunjukan bahwa ada kesesuaian antara harapan dan kenyataan pada penerapan Tri Hita Karana di Satria Agrowisata. Hubungan antara penerapan Tri Hita Karana dengan manajemen pada Satria Agrowisata sangat lemah namun pengunjung merasa sangat puas. Saran-saran yang dapat diberikan yaitu terus mempertahankan penerapan Tri Hita Karana pada kegiatan yang ada di Satria Agrowisata khususnya, memperbaiki hubungan antara penerapan Tri Hita Karana dalam manajemen pada Satria Agrowisata, dan mempertahankan ataupun meningkatkan kualitas pelayanan dan menambah variasi minuman serta makanan yang bisa dijual ke pengunjung.
\end{abstract}

Kata kunci: Tri Hita Karana, Manajemen, Satria Agrowisata 


\section{PENDAHULUAN}

\section{Latar Belakang}

Bali mempunyai luas wilayah $5.561 \mathrm{~km}^{2}$ atau 0,3 persen dari keseluruhan luas Negara Indonesia. Bali merupakan salah satu dari 34 provinsi yang ada di Indonesia. Sebelah Utara Pulau Bali adalah Laut Bali dan sebelah selatan adalah Samudra Hindia, sebelah barat Pulau Bali terdapat Pulau Jawa yang dipisahkan oleh Selat Bali, dan di sebelah timur terdapat Pulau Lombok yang dipisahkan oleh Selat Lombok. (Soesandireja, 2012).

Provinsi Bali telah menjadikan Tri Hita Karana sebagai landasan pembangunannya, yang tercermin dari visi pembangunan Provinsi Bali tahun 2006-2026 yakni:"Bali Dwipa Jaya, Adil, dan Demokratis, serta Aman dan Bersatu, Dalam Wadah Negara Kesatuan Republik Indonesia, maka Tri Hita Karana wajib diterapkan pada berbagai kegiatan kemasyarakatan seperti politik, ekonomi, sosial, pertahanan, serta keamaanan masyarakat (Windia dan Dewi, 2011).

Satria Agrowisata merupakan salah satu agrowisata yang ada di Bali dan merupakan wisata yang cukup populer sehingga didatangi oleh banyak wisatawan mancanegara maupun domestik. Agrowisata yang berlokasi di Banjar Basangambu, Desa Tampaksiring, Kecamatan Tampaksiring ini mempunyai produk yang menjadi ciri khasnya yaitu kopi luwak. Selain sebagai tempat wisata, Satria Agrowisata juga dapat menjadi tempat belajar untuk para wisatawan asing ataupun lokal yang datang berkunjung. Satria Agrowisata sebelumnya merupakan kebun kopi namun tidak produktif, dan kemudian oleh pemiliknya dijadikan agrowisata dan diberi nama Satria Agrowisata. Satria Agrowisata sudah menerapkan konsep Tri Hita Karana namun dalam penerapannya ada yang tidak sesuai dengan harapan, seperti dalam penerapan manajemen (penempatan para pemandu).

\section{Tujuan Penelitian}

Berdasarkan uruaian diatas maka tujuan penelitian, yaitu (1) menganalisis kesesuaian antara harapan dan kenyataan pada penerapan Tri Hita Karana di Satria Agrowisata, (2) menganalisis hubungan penerapan Tri Hita Karana dengan manajemen Satria Agrowisata, dan (3) menganalisis kepuasaan konsumen terhadap kegiatan agrowisata di Satria Agrowisata yang menerapkan Tri Hita Karana.

\section{METODE PENELITIAN}

\section{Lokasi dan Waktu Penelitian}

Teknik penentuan lokasi penelitian berdasarkan atas pertimbangan tertentu berfokus pada tujuan tertentu. Penelitian ini dilakukan di Satria Agrowisata dengan pertimbangan sebagai berikut.

1. Pemilik bersedia tempatnya untuk dijadikan penelitian dengan syarat tanpa melihat data keuangan perusahaan.

2. Mempunyai berbagai macam pengunjung dari lokal maupun manca negara

3. Sudah menerapkan Tri Hita Karana
Penelitian dilakukan selama tiga bulan dari bulan Juni hingga Agustus 2018.

\section{Metode Penentuan Sampel}

Dalam penelitian ini digunakan dua macam penentuan sampel yaitu sensus sampling dan accidental sampling. Jumlah responden yang digunakan adalah 94 orang dengan rincian 30 orang karyawan Satria Agrowisata termasuk pemilik, 10 orang pemandu wisata, 9 orang mitra Satria Agrowisata, dan 45 orang pengunjung Satria Agrowisata.

\section{Jenis dan Sumber Data}

Jenis data dalam penelitian ini meliputi:

a. Data kualitatif

Data kualitatif meliputi kondisi dari implementasi Tri Hita Karana di Satria Agrowisata.

b. Data kuantitatif

Data yang terkait dengan karakteristik pemiliki Satria Agrowisata, karakteristik karyawan, dan karakteristik pengunjung, serta data-data lain yang terkait dengan tujuan penelitian.

Sumber data dalam penelitian ini meliputi:

a. Data primer

Data primer diperoleh dari pemilik, para karyawan, mitra, pemandu wisata, dan pengunjung.

b. Data sekunder

Data sekunder diperoleh dari hasil dokumentasi, buku-buku, jurnal, artikel yang berhubungan dengan Tri Hita Karana dan manajemen.

\section{Variabel penelitian dan Teknik Pengumpulan Data}

Variabel penelitian yaitu unsur Tri Hita Karana, manajemen, dan kepuasan konsumen. Pengumpulan data pada penelitian ini menggunakan beberapa metode, yaitu.

a. Observasi (pengamatan)

Dalam penelitian ini observasi dilakukan untuk mengetahui keadaan dari Satria Agrowisata.

b. Wawancara (interview)

Wawancara dilakukan pada pemilik Satria Agrowisata dan karyawannya serta pengunjung.

c. Dokumentasi

Dokumentasi di perlukan agar penelitian yang dilakukan lebih dipercaya atau kredibel. Dokumentasi pada penelitian ini berupa foto-foto.

\section{Metode analisis Data}

Untuk menganalisis data, penelitian ini menggunakan metode analisis deskripstif kualitatif dan korelasi Rank Spearman yang di bantu dengan SPSS.

a. Deskriptif kualitatif

Prasetyo (2016) metode deskriptif adalah pencarian fakta dengan interpretasi yang tepat. Kegiatan ini meliputi pengumpulan data, analisis data, interpretasi data, dan dirumuskan pada suatu kesimpulan. Deskriptif kualitatif digunakan untuk mengetahui tujuan penelitian nomor satu dan tiga.

b. Korelasi Rank Spearman

Korelasi Spearman Rank atau Rank Spearman digunakan untuk mencari hubungan atau menguji signifikasi hipotesis asosiatif bila masing-masing 
variabel yang dihubungkan berbentuk ordinal dan sumber data antar variabel tidak harus sama (Sugiyono, 2013). Korelasi rank spearman digunakan untuk mencari tujuan penelitian nomor dua.

\section{HASIL DAN PEMBAHASAN}

\section{Karakteristik Responden}

Responden pada penelitian ini di bagi menjadi tiga yaitu responden pemilik dan karyawan, responden mitra dan pemandu wisata, serta responden pengunjung. Berikut ini adalah penjelasan dari masing-masing responden.

\section{Responden menurut jenis kelamin}

Responden menurut jenis kelamin meliputi:

a. Pemilik dan karyawan Satria Agrowisata

Jumlah responden yang ditetapkan dalam penelitian ini yaitu 30 orang yang terdiri dari karyawan dan pemilik dengan rinciannya terlihat pada Tabel 1 .

Tabel 1. Jenis Kelamin Pemilik dan Karyawan Satria Agrowisata

\begin{tabular}{ccrr}
\hline No & $\begin{array}{c}\text { Jenis } \\
\text { Kelamin }\end{array}$ & Jumlah & Persentase (\%) \\
\hline 1 & Wanita & 17 & 56,67 \\
\hline 2 & Pria & 13 & 43,33 \\
\hline & Total & 30 & 100,00 \\
\hline
\end{tabular}

Sumber: Data primer diolah

Berdasarkan Tabel 1 dapat diketahui bahwa karyawan wanita lebih banyak dari pada karyawan pria. Hal ini terkait dengan kualitas pelayanan yang diberikan oleh karyawan wanita, dimana wanita lebih terampil dan menarik dalam memberikan pelayanan kepada konsumen.

b. Mitra dan pemandu wisata

Pada responden mitra usaha dan pemandu wisata saat dilakukan penelitian, semua respondennya berjenis kelamin pria, dengan rincian responden mitra usaha berjumlah 9 orang pria dan responden pemandu wisata berjumlah 10 orang pria. Hal ini terkait dengan peran pria dalam keluarga menjadi kepala rumah tangga. Mitra usaha Satria Agrowisata dalam penelitian ini adalah penyedia jasa tour and travel. Pemandu wisata di Bali lebih banyak berjenis kelamin pria, hal ini dikarenakan pria lebih menyukai pekerjaan lepas atau tidak terikat dalam ruangan, dan lebih senang berada diluar ruangan.

c. Pengunjung Satria Agrowisata

Jumlah responden pengunjung Satria Agrowisata yang telah di teliti yaitu 45 orang dengan rinciannya terlihat pada Tabel 2.

Tabel 2. Jenis Kelamin Pengunjung Satria Agrowisata

\begin{tabular}{cccr}
\hline No & $\begin{array}{c}\text { Jenis } \\
\text { Kelamin }\end{array}$ & Jumlah & \multicolumn{1}{c}{$\begin{array}{c}\text { Persentase } \\
(\%)\end{array}$} \\
\hline 1 & Wanita & 26 & 57,78 \\
\hline 2 & Pria & 19 & 42,22 \\
\hline & Total & 45 & 100,00
\end{tabular}

Sumber: Data primer diolah
Berdasarkan Tabel 2 dapat dilihat bahwa pengunjung Satria Agrowisata kebanyakan wanita. Hal ini dikarenakan wanita lebih menyukai wisata yang aman dan nyaman, sehingga bisa dinikmatin sambil bersantai. Sementara pria lebih menyukai wisata yang ekstrem dan menantang.

\section{Responden menurut usia}

Responden menurut usia meliputi:

a. Pemilik dan karyawan Satria Agrowisata

Usia pemilik dan karyawan Satria Agrowisata berada diantara rentang umur 15 hingga 40 tahun. Hal ini membuktikan bahwa pemilik dan karyawan Satria Agrowisata masih berada pada usia produktif (umur 15 hingga 64 tahun) sehingga masih layak untuk bekerja bahkan sedang berada dalam kondisi yang bagus.

b. Mitra dan pemandu wisata

Usia responden mitra dan pemandu wisata berada pada usia produktif 26 hingga 55 tahun, sehingga mitra dan pemandu wisata dapat bekerja dengan baik.

c. Pengunjung Satria Agrowisata Pengunjung Satria Agrowisata mempunyai usia yang bervariasi dari umur 18 tahun hingga 58 tahun. Kebanyakan pengujung Satria Agrowisata datang dalam group atau lebih dari dua orang, bahkan ada yang datang bersama keluarganya. Pemilik dan karyawan Satria Agrowisata

\section{Kesesuaian Antara Harapan dan Penerapan}

Harapan merupakan suatu hal yang sangat didambakan atau di cita-citakan dengan kata lain sesuatu yang belum terjadi tetapi di inginkan agar terjadi. Sementara penerapan adalah mempraktekan suatu teori, metode untuk mencapai tujuan tertentu. Pada Tabel 3 menjelaskan kesesuaian antara harapan dengan penerapan pada penerapan Tri Hita Karana di Satria Agrowisata. Tabel 3. Kesesuaian antara Harapan dan Penerapan

\begin{tabular}{ccrr}
\hline No & Unsur Tri Hita & $\begin{array}{c}\text { Penerapan } \\
(\%)\end{array}$ & $\begin{array}{c}\text { Ket. } \\
*)\end{array}$ \\
\hline 1 & Parhyangana & & \\
& a. Karyawan & 100,00 & SS \\
& b. Mitra & 99,78 & SS \\
& c. Pemandu & 67,40 & CS \\
\hline 2 & Pawongan & & \\
& a. Karyawan & 92,87 & SS \\
& b. Mitra & 94,89 & SS \\
& c. Pemandu & 74,00 & S \\
\hline 3 & Palemahan & & \\
& a. Karyawan & 99,87 & SS \\
& b. Mitra & 100,00 & SS \\
& c. Pemandu & 84,00 & S \\
\hline
\end{tabular}

\footnotetext{
Sumber: Data primer diolah

*) Keterangan

SS = Sangat Sesuai

$\mathrm{S}=$ Sesuai

$\mathrm{CS}=$ Cukup Sesuai

Berdasarkan Tabel 3 dapat dilihat bahwa menurut karyawan Satria Agrowisata penerapan unsur parhyangan sangat sesuai antara harapan dan penerapan.
} 
Hal ini membuktikan bahwa Satria Agrowisata sudah menerapkan Tri Hita Karana dengan sangat baik karena ada kesuaian antara harapan dan penerapan. Seperti contoh karyawan Satria Agrowisata melakukan maturan keliling setiap hari, setiap plangkiran dan tempat suci dihaturkan banten atau canang sari. Kemudian sebelum Satria Agrowisata dibuka, para karyawan diajak sembahyang terlebih dahulu baru kemudian melakukan aktifitas.

Untuk unsur pawongan menurut mitra Satria Agrowisata penerapan yang dilakukan sangat sesuai antara harapan dengan penerapan. Seperti halnya, saat mendapat undangan menyama braya maka Satria Agrowisata akan menugaskan beberapa karyawannya untuk memenuhi undangan tersebut. Tidak jarang Satria Agrowisata mendapat undangan dari mitra ataupun pemandu wisata yang sudah sering mengajak tamu ke Satria Agrowisata. Hal ini bisa mempererat hubungan antara Satria Agrowisata dengan mitra, pemandu, warga sekitar dan karyawannya. Selain membantu warga sekitar dengan bergotong-royong jika ada acara, Satria Agrowisata juga mengajarkan bahasa asing kepada anak-anak warga sekitar, dan mereka bisa mempraktekannya di Satria Agrowisata ketika bertemu dengan pengunjung dari luar negeri.

Unsur palemahan menurut karyawan dan mitra penerapan yang dilakukan sangat sesuai antara penerapan dan harapan. Satria Agrowisata berkeinginan untuk memperkenalkan tanaman-tanaman yang tumbuh di Indonesia dan beberapa diantaranya digunakan menjadi bahan dasar produk minuman yang ada di Satria Agrowisata. Contohnya tanaman kopi, tanaman coklat, tanaman temulawak, tanaman nanas, tanaman jambu air, tanaman pepaya, tanaman sereh, tanaman kelapa, tanaman rosella, dan masih banyak lagi. Tanamantanaman tersebut diatur sedemikian rupa sehingga dari baru masuk Satria Agrowisata, para pengunjung dapat melihat tanaman-tanaman tesebut dan mendapat penjelasan dari para pemandu wisata mereka tentang nama tanaman, manfaat, dan menjadi bahan produk.

\section{Hubungan Penerapan Tri Hita Karana dengan Manajemen}

Untuk mengetahui hubungan penerapan Tri Hita Karana dengan manajemen, digunakanlah analisis Rank Spearman karena data penelitian menggunakan skala ordinal. Tujuan analisis menggunakan Rank Spearman adalah untuk melihat tingkat kekuatan dua variable dan melihat arah hubungan. Pada Tabel 4 menjelaskan korelasi antara unsur Tri Hita Karana (parhyangan, pawongan, dan palemahan) dengan unsur manajemen (planning, organizing, actuating, dan controlling) yang dihitung dengan cara analisis Rank Spearman menggunakan SPSS.
Tabel 4. Korelasi Rank Spearman

\begin{tabular}{lrrr}
\hline \multirow{2}{*}{ Manajemen } & \multicolumn{3}{c}{ Tri Hita Karana } \\
\cline { 2 - 4 } & Parhyangan & Pawongan & Palemahan \\
\hline $\mathrm{r}$ & $-0,082$ & $-0,021$ & $-0,082$ \\
\hline Sig. & 0,621 & 0,901 & 0,621 \\
(2-tailed) & & & 39 \\
\hline $\mathrm{N}$ & 39 & 39 &
\end{tabular}

Sumber: Data primer diolah

Pada Tabel 4 semua unusr dalam Tri Hita Karana mempunyai angka korelasi negatif. Hal ini menunjukkan hubungan semua unsur dengan manajemen lemah. Dari ketiga unsur tersebut, hubungan antara parhyangan dengan manajamen dan palemahan dengan manajemen sangat lemah.

Hal ini dapat disebabkan oleh sistem manajemen yang belum jelas, seperti contoh seorang manajer mempunyai tugas yang seharusnya dikerjakan oleh empat orang manajer yang berbeda. Contoh lainnya adalah pembagian tugas kepada karyawan yang belum jelas, hal ini juga dapat membuat sistem manajemen menjadi sangat lemah.

Tanda negatif pada koefisien korelasi rank Spearman (r) menunjukkan bahwa unsur Tri Hita Karana dengan manajemen mempunyai arah yang berbeda, yang artinya kegiatan Tri Hita Karana yang ada di Satria Agrowisata mempunyai hubungan yang sangat lemah dengan manajemen yang diterapkan di Satria Agrowisata. Nilai Sig. pada parhyangan, pawongan, dan palemahan berada diatas 0,05 yang artinya bahwa hubungan antara Tri Hita Karana dengan manjemen tidak signifikan atau tidak berarti.

Berdasarkan hasil penelitian yang telah dilakukan, maka terdapat hubungan yang sangat lemah antara penerapan Tri Hita Karana dengan manajemen di Satria Agrowisata. Dalam suatu perusahaan yang sudah menerapkan Tri Hita Karana, maka manajemen yang diterapkan seharusnya berhubungan kuat dengan Tri Hita Karana tersebut. Namun pada Satria Agrowisata, penerapan Tri Hita Karana dengan manajemen mempunyai hubungan yang sangat lemah. Hal ini bisa disebabkan karena Satria Agrowisata mempunyai sistem manajemen yang belum begitu jelas, seperti contoh penempatan dan tugas karyawan.

Pada Satria Agrowisata ada beberapa jenis pekerjaan seperti mencuci peralatan, merawat tanaman, melayani tamu, membuat minuman, menjaga kasir atau toko sovenir, mengemas produk, tukang parkir, membanten atau maturan, dan menyambut tamu. Jika tamu atau pengunjung yang datang pada satu hari jumlahnya lebih dari karyawan yang mampu menangani, maka karyawan yang berada dibagian mengemas produk akan turut membantu untuk melayani tamu, dan apabila tamu atau pengunjung sudah berkurang, maka karyawan tersebut akan kembali kebagian mengemas produk.

Begitu juga jika produk yang harus dikemas dalam jumlah banyak, dan pengunjung yang datang tidak terlalu banyak, maka beberapa karyawan yang mempunyai tugas yang lain akan membantu karyawan bagian pengemasan 
untuk mengemas produk. Satria Agrowisata mengharuskan para karyawannya untuk selalu siap saling membantu walaupun hal tersebut bukan bagian dari pekerjaanannya. Seperti karyawan yang bertugas membanten atau maturan keliling, jika karyawan tersebut telah selesai maturan keliling, maka karyawan tersebut akan kembali ke bagian pekerjaan sebelumnya, misalnya menerima tamu atau pengunjung, melayani pengunjung, mengemas produk, dan mencuci peralatan.

\section{Kepuasan Konsumen Terhadap Manajemen Yang} Menerapkan Tri Hita Karana

Kepuasan konsumen atau pengunjung merupakan salah satu tujuan dari Satria Agrowisata. Kepuasan pengunjung Satria Agrowisata berada di tingkat puas dengan nilai tertingi sebesar $93,09 \%$ merasa sangat puas dengan pelayanan yang ada di Satria Agrowisata. Hal ini membuktikan bahwa Satria Agrowisata merupakan Agrowisata yang pantas untuk dikunjungi, karena pelayanan yang diberikan berbeda dengan agrowisata yang lain dan hal ini sudah dibuktikan oleh 55 responden kepuasan pengunjung Satria Agrowisata (dengan rincian 45 orang pengunjung dan 10 orang pemandu wisata). Hal ini juga membuktikan bahwa salah satu tujuan yang ingin dicapai oleh Satria Agrowisata sudah terwujud, tinggal dipertahankan dan semakin ditingkatkan lagi. Agar bisnis yang ada di Satria Agrowisata dapat berjalan dengan lancar dan berkembang pesat.

Indikator aura spritual mendapat nilai terkecil yairu $88,72 \%$. Hal ini disebabkan pengunjung yang datang ke Satria Agrowisata kebanyakan mempunyai tujuan untuk mencicipi kopi luwak yang ada di Satria Agrowisata, sehingga untuk merasakan aura spritual tidak begitu diperhatikan

\section{Simpulan dan Saran}

\section{Simpulan}

Berdasarkan hasil penelitian yang diuraikan sebelumnya maka disimpulkan hal-hal sebagai berikut: kesesuaian antara harapan dan penerapan Tri Hita Karana di Satria Agrowisata sudah sangat sesuai, hubungan yang dimiliki antara Tri Hita Karana dengan manajemen pada Satria Agrowisata sangat lemah, dan rata-rata responden pengunjung Satria Agrowisata merasa sangat puas terhadap kegiatan agrowisata di Satria Agrowisata yang menerapkan Tri Hita Karana.

\section{Saran}

Berdasarkan uraian penelitian dan kesimpulan sebelumnya, maka dapat diberikan saran-saran sebagai berikut: untuk terus mempertahankan kesesuaian antara harapan dan penerapan berdasarkan penerapan Tri Hit Karana di Satria Agrowisata, dalam memperbaiki hubungan antara penerapan Tri Hita Karana dengan manajemen pada Satria Agrowisata. perlu membuat sistem manajemen yang lebih jelas seperti dalam penempatan dan penugas karyawan, sehingga karyawan dapat bekerja dengan maksimal, dan Satria Agrowisata perlu mempertahankan atau bahkan meningkatkan kualitas pelayanan dan menambah variasi minuman serta makanan yang bisa dijual ke pengunjung, sehingga pengunjung bisa merasa lebih puas dikarenakan banyaknya variasi minuman dan makanan yang ditawarkan.

\section{Daftar Pustaka}

Antara, M. 2011. Modul Metode Penelitian Cetakan ke II, Denpasar: Universitas Udayana.

Prasetyo, A. 2016. Pengertian Penelitian Deskriptif Kualitatif, Availabel from: URL: http://linguistikd.blogspot.co.id.

Soesandireja. 2012. Mengenal Budaya Bali Lebih Dekat; Manusia, Alam dan Dewa. Availabel: from URL http://www.wacana.co.

Sugiyono. 2013. Statistik Nonparametrik Untuk Penelitian, Bandung: Alfabeta.

Sugiyono. 2017. Metode Penelitian Kualitatif Bandung: Alfabeta.

Teguh. 2001. Metode Penelitian Kuantitatif, Bandung: Alfabeta.

Windia, W. dan Dewi, R. K. 2011. Analisis Bisnis Berlandaskan Tri Hita Karana. Denpasar: Univ Udayana.

Wirawan. 2002. Statistik Penelitian Kuantiatif dan Kualitatif, Bandung: Alfabeta 